\title{
Extrasynovial Synovial Osteochondromatosis of the Ankle: A case report
}

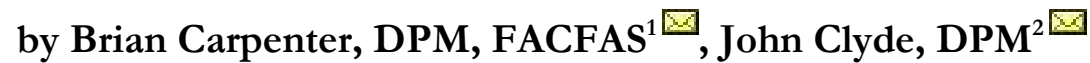

The Foot and Ankle Online Journal 3 (6): 3

Synovial osteochondromatosis has been widely described in the literature. In published journals, it is referred to as synovial chondromatosis, synovial chondrometaplasia and synovial osteochondromatosis. Most cases involve multiple osteocartilagenous bodies within a joint, however there are multiple cases published of this disease affecting extraarticular spaces around joints, bursal areas, and tendon sheaths. Interestingly, published cases with extrasynovial involvement at the ankle joint were encountered twice on a broad search. Of the two cases, only one was solely extraarticular, the other case described both intra and extraarticular involvement. $^{1,2}$ The rarity of this diagnosis in the literature spurred us to report our case of extrasynovial synovial osteochondromatosis of the ankle.

Key words: Synovial osteochondromatosis, extrasynovial, ankle.

Accepted: May, 2010

Published: June, 2010

This is an Open Access article distributed under the terms of the Creative Commons Attribution License. It permits unrestricted use, distribution, and reproduction in any medium, provided the original work is properly cited. (The Foot and Ankle Online Journal (www.faoj.org)

S ynovial Osteochondromatosis is a benign process of synovial proliferation which leads to osteocartilaginous bodies being present within a synovial space, usually a joint. According to Milgram, the disease has three phases. There is a progression with each phase starting with proliferation from the synovial membrane with adhered cartilaginous bodies, a transitional phase with osteocartilaginous nodules adhered to and free from the synovium, and finally loose osteocartilaginous bodies free from the synovium with central calcification. The free bodies can be reattached to the synovium, can conglomerate, can break through the joint capsule, and can be reabsorbed based on Milgram's case series. ${ }^{3}$

\footnotetext{
Address correspondence to: Brian Carpenter, DPM, FACFAS . John Peter Smith Hospital, 1500 South Main Street, Fort Worth, TX 76104. bcarpent@jpshealth.org

${ }^{1}$ Associate Professor, University of North Texas Health Science Center, Residency Director, John Peter Smith Hospital, Department of Orthopedics, Podiatry Division, 1500 South Main Street, Ft. Worth, TX 76104 2 PGY-1, John Peter Smith Hospital, Department of Orthopedics, Podiatry Division, 1500 South Main Street, Ft. Worth, TX 76104.
}

\section{Case Report}

A 56 year-old female with history of trauma to the left ankle and greater than four year history of pain and increasing soft tissue mass at the anteromedial left ankle presents for evaluation. She notes that the lesion has been slowly increasing over time and she has pain associated with dorsiflexion of the ankle and has problems finding accommodative shoe gear. This lesion is well circumscribed, nodular and firm and is in the distal course of the anterior tibial tendon. Palpation of the lesion does not elicit pain; however the patient has decreased range of motion on dorsiflexion of the ankle and discomfort associated with this range of motion. 


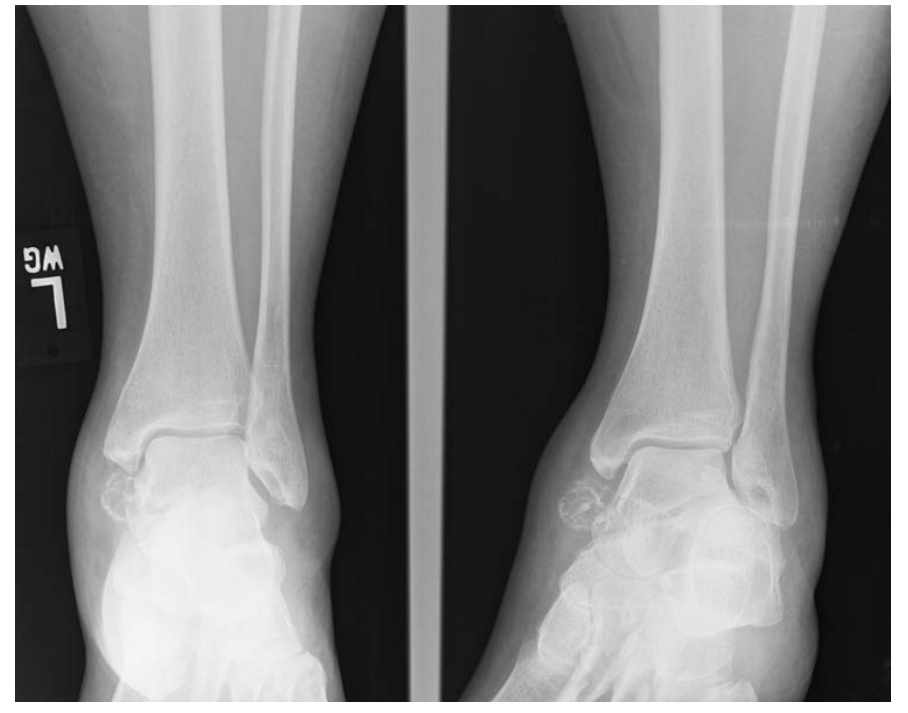

Figure 1 Notable well-circumscribed calcific density on radiograph.

Radiographic analysis of the ankle reveals a radioopaque calcific nodule (Fig. 1) anterior to the medial malleolus and dorsal to the talar neck. MRI analysis shows an encapsulated mass external to the ankle joint capsule with an inhomogeneous internal signal measuring 1.6X1.5X2.2 cm. (Fig. 2) The mass is viewed on multiple planes and cuts and has a fatty capsule with surrounding edema, the composition of the mass has parts which are isointense with bone and cartilage on multiple spins, the remainder of the lesion does not appear to be isointense with other tissues and did not have a fluid density. Based upon these findings, the provisional diagnosis of chronic calcific ganglion was chosen since there was not a classic pattern of cartilage capsule with central ossification as in synovial osteochondromatosis. The patient was scheduled for outpatient surgical resection of the mass after all risks and benefits were discussed. Once the anteromedial ankle incision was made an extremely firm, encapsulated mass measuring $3 \times 2 \times 2 \mathrm{~cm}$ was encountered external to the ankle joint capsule and free from the anterior tibial tendon. Once sent to histopathology (Figs. 3), with the combination of osteoid and cartilage present in the specimen combined with our physical and radiological exam, the diagnosis of extrasynovial synovial osteochondromatosis was made.

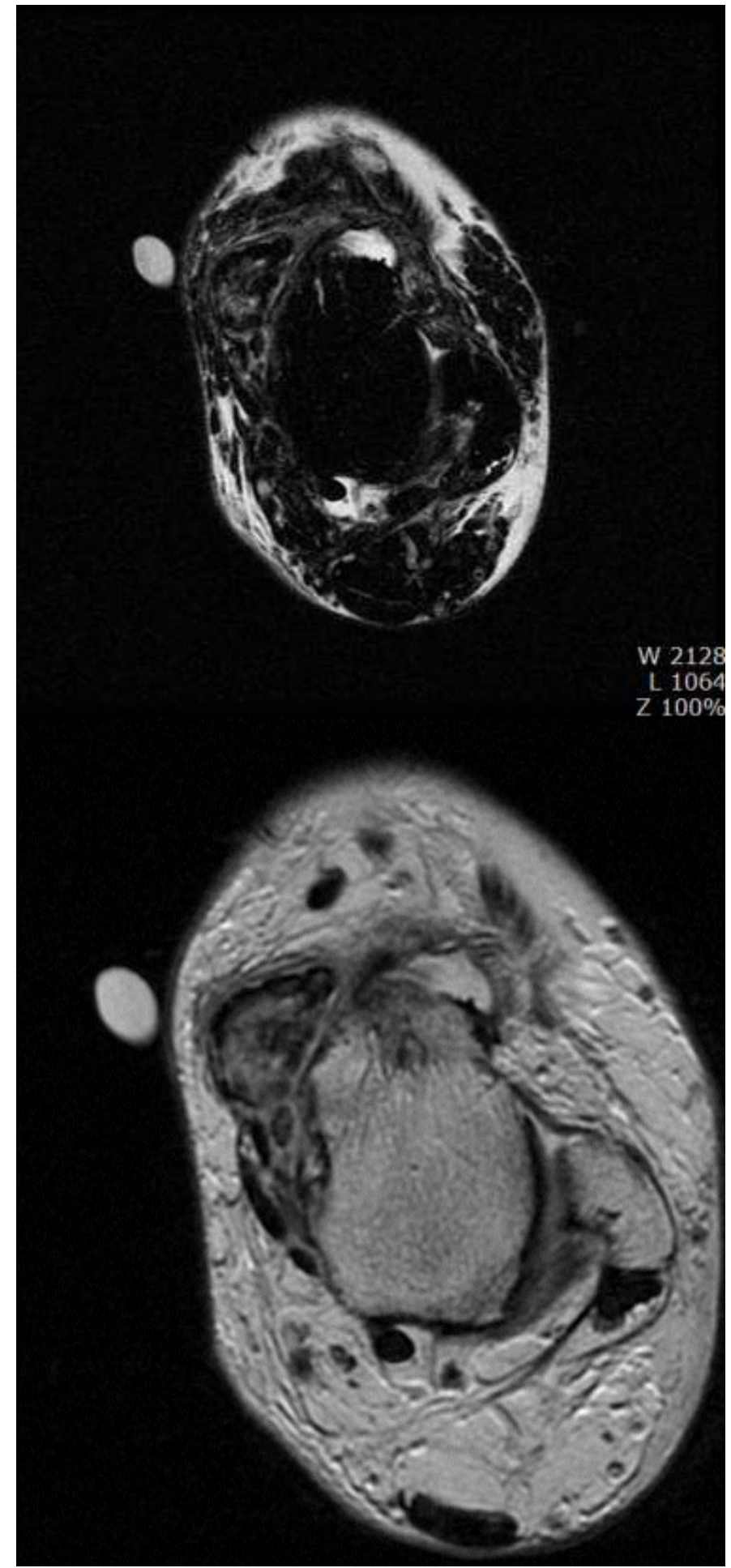

Figure 2 Variable cut and spin magnetic resonance imaging sequences showing the inhomogeneous structure. (See marker) 


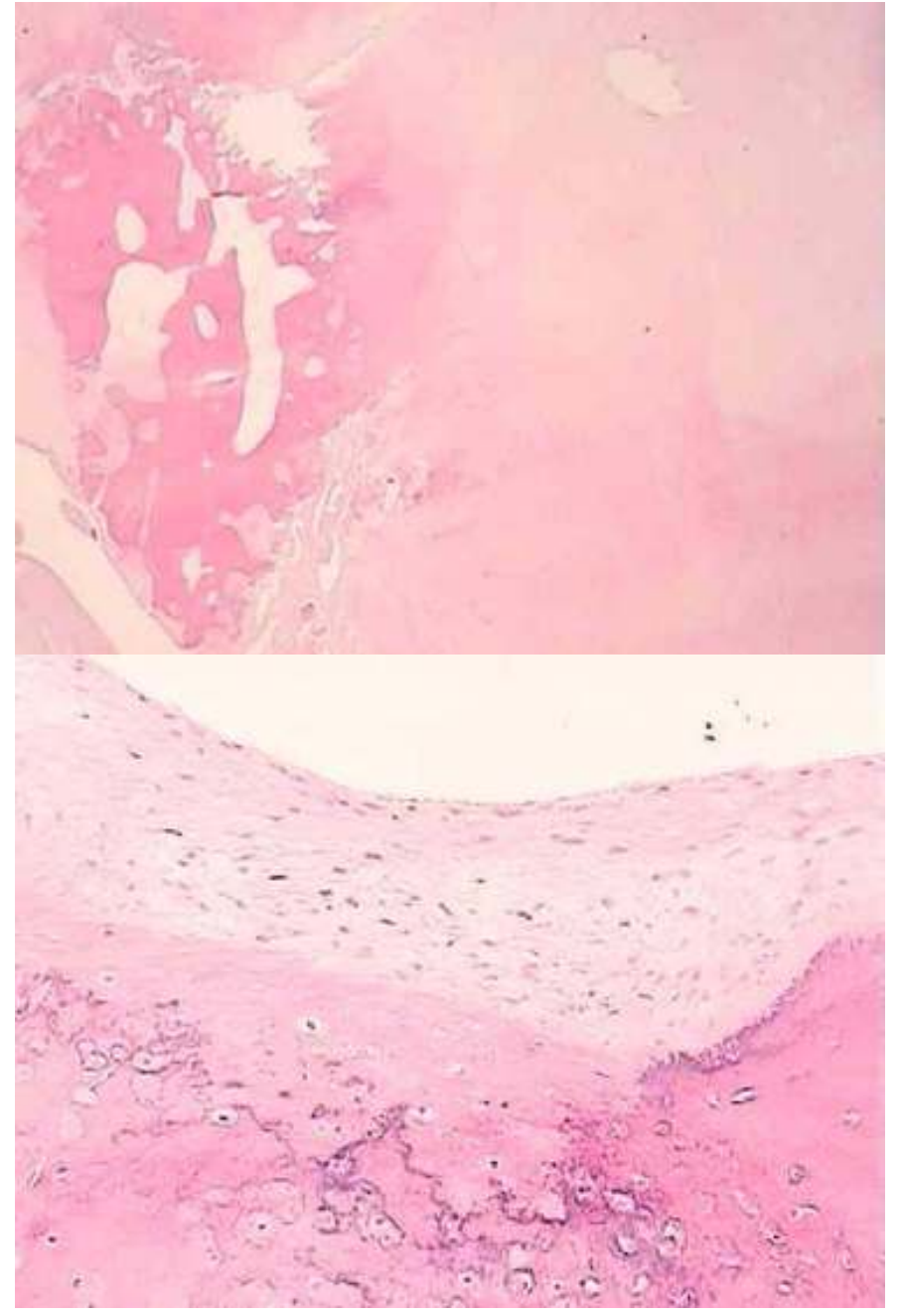

Figures 3 Evidence of osteoid, cartilaginous and fibroconnective tissue.

At nine months postoperatively, the patient is asymptomatic with no evidence of recurrence on serial physical examination and radiography.

\section{Discussion}

By histological analysis and prior published cases, intrasynovial involvement need not be present for diagnosis of synovial osteochondromatosis. ${ }^{3,45}$ Milgram describes 4 types of the disease including presence in a normal joint, presence in a degenerated joint, presence in a tendon sheath and presence in extraarticular bursal areas. ${ }^{5}$
In our patient, synovial osteochondromatosis may have been more easily diagnosed early on, if numerous densities were noted on plain film within the ankle joint. ${ }^{6,8}$ Through physical exam, radiography, magnetic resonance imaging (MRI)and histopathology a proper diagnosis could be made. The natural history of the disease process as described by Milgram is self- limiting and generally the loose bodies are extruded from the synovium however not from the joint. ${ }^{3}$ In our case, the size of the lesion may have caused it to be extruded from the ankle joint or a synovial lined tendon sheath to make it extrasynovial. Malignant transformation is a concern, with $5 \%$ possibility of transformation, and recent efforts have been made to find markers to differentiate disease processes to better predict transformation. ' Close post-operative follow-up is recommended as cases reviewed involving malignant transformation dealt with recurrent osteochondromatosis prior to the ultimate diagnosis of chondrosarcoma. ${ }^{9}$

\section{References}

1. Tibrewal, SB, Iossifidis, A. Extra-articular synovial chondromatosis of the ankle. JBJS 1995 77B: 659-660.

2. Pathak, SS, Joseph, C, Aravinda, M, Sonar, S, Vinodh, K, Rajan, D. A case of primary intraarticular and extra articular synovial chondromatosis of ankle and foot. The Internet Journal of Orthopedic Surgery 20074 (1).

3. Milgram JW. Synovial osteochondromatosis: a histopathological study of thirty cases. JBJS 1977 59A: 792-801.

4. Milgram JW, Hadesman WM. Synovial osteochondromatosis in the subacromial bursa. Clin Orthop 1988 236: 154-159.

5. Hashimoto, N, Okada, K. Synovial osteochondromatosis of the retrocalcaneal bursa: a case report. JBJS 1996 78A(11): 17411745.

6. Shearer, H, Stern, P, Brubacher, A, Pringle, T. A case report of bilateral synovial chondromatosis of the ankle. Chiropr Osteopat 2007 15:18.

7. Yu, GV, Zema, RL, Johnson, RWS. Synovial osteochondromatosis: a case report and review of the literature JAPMA 2002 92: 247-254.

8. Lee, DK, Louk, L, Bell, BL. Synovial osteochondromatosis involvement in post-traumatic ankle injury. JAPMA 2008 98: 7074.

9. Sperling, BL, Angel, S, Grant, S, Chow, V, Mcfadden, A, Chibbar, R. Synovial chondromatosis and chondrosarcoma: a diagnostic dilemma. Sarcoma 20037 (2): 69-73. 